\title{
Article \\ Determinants of the Intention to Use Cross-Border Mobile Payments in Korea among Chinese Tourists: An Integrated Perspective of UTAUT2 with TTF and ITM
}

\author{
Run-Ze Wu ${ }^{1}$, Jong-Ho Lee ${ }^{2}$ and Xiu-Fu Tian ${ }^{3, *}$ \\ 1 College of Economics, Jiaxing University, Jiaxing 314001, China; w3140025@naver.com \\ 2 Electronic Commerce, Kongju National University, Kongju 32588, Korea; leejh@kongju.ac.kr \\ 3 College of Business, Jiaxing University, Jiaxing 314001, China \\ * Correspondence: txf358813886@zjxu.edu.cn
}

Citation: Wu, R.-Z.; Lee, J.-H.; Tian, X.-F. Determinants of the Intention to Use Cross-Border Mobile Payments in Korea among Chinese Tourists: An Integrated Perspective of UTAUT2 with TTF and ITM. J. Theor. Appl. Electron. Commer. Res. 2021, 16, 1537-1556. https://doi.org/ 10.3390/jtaer16050086

\section{Academic Editors:}

Agnieszka Głodowska and

Krzysztof Wach

Received: 30 March 2021

Accepted: 7 May 2021

Published: 12 May 2021

Publisher's Note: MDPI stays neutral with regard to jurisdictional claims in published maps and institutional affiliations.

Copyright: (C) 2021 by the authors Licensee MDPI, Basel, Switzerland. This article is an open access article distributed under the terms and conditions of the Creative Commons Attribution (CC BY) license (https:/ / creativecommons.org/licenses/by/ $4.0 /)$.

\begin{abstract}
With the acceleration of global economic integration and digital economy, cross-border mobile payment has gained growing attention. On the other hand, as COVID-19 keeps on spreading, the popularization of cross-border mobile payment can lower the risk of infection caused by cash payment of tourists. However, though previous researchers already examined mobile payment users' behavioral intention from different perspectives, these research findings tend to concentrate on the non-cross-border section of mobile payment. Therefore, the purpose of this research is to examine factors influencing cross-border mobile payment use intention from the user perspective, and combining three theoretical models, chiefly UTAUT2 (extended unified theory of acceptance and use of technology), ITM (initial trust model), and TTF (task technology fit). In this research, 786 Chinese with the experience of using cross-border mobile payment while traveling to South Korea are adopted as respondents, and the structural equation model is used to empirically analyze the data of these research samples. The study found that initial trust, performance expectancy, effort expectancy, facilitating conditions, price value, task technology fit, and initial trust have significant effects on use intention. Research findings of this paper can deepen people's understanding of users' intention to use cross-border mobile payment, and provide theoretical support for the development of cross-border mobile payment.
\end{abstract}

Keywords: cross-border mobile payment; UTAUT2; TTF; ITM; use intention; integrated model

\section{Introduction}

Technological progress can provide a wide range of functions for mobile equipment and support multiple mobile financial services, such as bill payment, account transfer, payment at points of sales, and remote payment services [1], and other types of services, such as positioning-based mobile marketing, ticket, discount, or coupon [2]. The extensive use and popularity of mobile devices enables people to use mobile payment without taking the wallet with them, thus equipping smartphones with real commercial value in mobile payment [3].

Mobile payment saves consumers the trouble of using cash. An increasing number of users hope that they acquire more convenient and safe payment experience in the mobile payment process. All this suggests that mobile payment is changing the way how people live [4].

With an increasing number of Chinese traveling abroad, applications of mobile payment abroad have become more and more frequent [5]. Meanwhile, China has become the country with the largest number of tourists traveling to South Korea, thus, the influence of cross-border mobile payment services on the payment mode of Chinese tourists to South Korea will be strengthening [6]. 
User demand is the core element that can effectively promote cross-border mobile payment $[7,8]$. It is believed that improvement of the factors affecting use of cross-border mobile payment among Chinese traveling to South Korea can boost the use of cross-border mobile payment in the future. From the perspective of practical applications, though Chinese tourists have been using mobile payment more and more frequently, safety loopholes and limited cross-border services of mobile payment have also hindered the popularization and promotion of mobile payment [1]. On the other hand, there are many users still regarding mobile payment as an extension of the traditional payment mode by cash or as a supplementation to the current payment mode, which is adopted only under specific contexts (such as in China). User demand is a core element that can effectively propel the development of cross-border mobile payment [8]. Users' adoption and use behaviors can directly decide the position of the future cross-border mobile payment in the offline payment market. At present, adoption behaviors and user intentions of mobile payment have been a general research interest, which has formed a large number of positive research findings. For example, Saprikis et al. [9] expanded the TAM model, and empirically analyzed the mobile consumers' shopping intention. Molina-Castilo et al. [10] analyzed learning costs for technologies after mobile payment user intention. Wei et al. [11] empirically examine young generation's mobile payment adoption behaviors based on the UTAUT. All this research is conducive to understanding payment users' demand preferences, and can provide valuable implications to the formulation of the mobile payment market strategies. Nevertheless, all this research targeting adoption behaviors and user intentions is still insufficient to achieve a deep understanding of cross-border mobile payment users' selection behaviors. In the current cross-border mobile payment market, user adoption and use rate of the cross-border mobile payment are still at a low level. A main reason behind the phenomenon is that the cross-border mobile payment is still in the initial development stage, when the social cognition is lacking, and the business model, service model, and monitoring system have lots to be desired. Thereby, the existing literature is inadequate to address the low adoption rate of cross-border mobile payment. Considering the research gap, this research aims at clarifying which factors can affect mobile payment user intentions. This necessitates further research of this issue. Though Chinese tourists visiting South Korea can use cross-border mobile payment services in South Korea, the cross-border mobile payment services have not yet covered every field of global mobile payment. Under the background that 5G, Internet of Things (IoT), and globalization are accelerating their development, this paper extends the research scope to factors influencing the global mobile payment use intention so as to make this research more systematic. It is also hoped that this research can lay a solid foundation for a follow-up investigation of sustainability of cross-border mobile payment.

Researchers of different fields have been searching factors affecting the intention to use, but empirical research of cross-border mobile payment is still insufficient. Considering the research limitation of cross-border mobile payments, this research attempts to study the extended unified theory of acceptance and use of technology (UTAUT2) from multiple theoretical perspectives. In order to gain a deeper understanding of factors affecting the adoption of cross-border mobile payment, and strengthening the importance and predictability of results, this paper holds that the integrated model, in comparison with the single model, can provide more valuable insights. Second, little research attention has been paid to cross-border mobile payment users. Cross-border mobile payment is an aspect of the mobile payment field, which has not yet been fully developed. By studying the crossborder mobile payment, this paper attempts to gain a more comprehensive understanding of the mobile payment field so as to fill in the research gap of mobile payment in the crossborder field. In order to address research limitations of relevant fields, this paper combines initial trust model (ITM) and task technology fit (TTF) with UTAUT2 to effectively make up respective limitations of three independent models, and use the integrated model as the research model. 
Among overseas tourists to South Korea, Chinese tourists take up the highest percentage. This research takes Chinese tourists traveling to South Korea as respondents. Analysis results can help scholars and cross-border mobile payment service providers gain a better understanding of which influencing factors can significantly improve the user intention. This is critical to the development of cross-border mobile payment services.

This paper consists of five sections. The current section is Section 1. Section 2 provides the theoretical basis for mobile payment, UTAUT2, TFF, and ITM. Section 3 presents the research models and hypotheses proposed on the basis of the theoretical background. Section 4 provides the analysis methods to verify the hypotheses, and results of empirical analysis. Section 5 discusses the research results, and points out the theoretical and practical contributions, research limitations, and prospects of this research.

\section{Theoretical Background}

\subsection{Mobile Payment}

Mobile payment refers to a mode of payment which pays the product or service purchased via mobile devices, PDA, mobile PC, and so on that have access to the Internet $[12,13]$. Mobile payment can mainly be divided into near-field payment and remote payment. By near-field payment, it means that the user takes the bus, buys goods, or has other activities by scanning the QR code on the mobile phone, which is very convenient $[14,15]$. Remote payment is to realize payment via sending of the payment instruction to the Internet bank, phone bank, mobile payment, etc. Compared with other payment modes, mobile payment has the advantage to trade in any place and at any period of time $[16,17]$. Organizations or individuals can send payment instructions to banks and other financial institutions to generate monetary payment and fund transfer behaviors to realize mobile payment functions $[18,19]$. Mobile payment is to provide monetary payment, payment of fees, and other financial services for users through the combination of terminal devices, Internet, app providers, and financial institutions [20,21].

\subsection{Task Technology Fit: TTF}

The theory of "task technology fit (TTF)" was first developed by Goodhue and Thompson [22], which can be used to measure whether technology can support users to finish tasks. The theory of TTF includes technology characteristics, task characteristics, and task technology fit. Technology characteristics mean that technology can support users to finish their desired tasks. For example, the mobile payment system allows users to finish relevant tasks. Task characteristics refer to tasks completed via technology. For example, Chinese traveling to South Korea hope that mobile payment satisfy part of their needs. TTF means to what degree that the new technology can meet user demand. If the functions of the technology are highly matched with user tasks, then users will use the technology more frequently [23]. Therefore, users adopt an information technology usually because the technology highly fits with their demand [24,25]. TTF can favorably explain users' use of an information system or service [26,27].

The theory of TTF, after being put forward, has found wide applications. Yen et al. [28] studied factors influencing users via TTF and TAM. Tam and Oliveira [29] explored users' applications of the mobile bank based on TTF.

\subsection{The Extended Unified Theory of Acceptance and Use of Technology: UTAUT2}

Venkatesh et al. [30] integrated eight basic theoretical models, including TRA, TAM, MM, TPB, MPCU, IDT, SCT, and so on, to develop the Unified Theory of Acceptance Use of Technology. In this paper, UTAUT integrates 32 influencing factors of eight theories into four core variables, including performance expectancy, effort expectancy, social influence, and facilitating conditions. The explanatory power of UTAUT is as high as $70 \%$, which is higher than any previous technical model. Therefore, UTAUT has found wide applications among the academic circles. 
Venkatesh et al. [31], on the basis of UTAUT, proposed UTAUT2, which studies consumer behaviors in information technological applications. UTAUT2 introduces three new variables, including hedonic motivation, price value, and habit, and proves that the newly-increased three variables play an important role in users' acceptance of information technology. UTAUT2, though introduced at a late date, and with a narrower scope of applications compared with UTAUT and TAM, has gained wide attention from mobile business researchers. Morosan and DeFranco [32] studied factors influencing use intention of NFC mobile payment. Alalwan et al. [33] carried out an empirical research of factors influencing use intention of online banks on the basis of UTAUT2.

\subsection{Initial Trust Model: ITM}

Since online trade involves a high uncertainty and risk, researchers are interested in studying trust in the mobile commerce environment [34,35]. The formation of trust is a dynamic process. It has been found that trust can affect users' acceptance of various services. Specifically, trust includes initial trust and continuous trust, of which initial trust is the most important stage of trust development [36,37]. As the first stage of trust development, initial trust plays an important role in users' behavioral intention, and various factors influencing initial trust are pinpointed at this stage. Influence factors of the first type are related to consumers. Personal propensity to trust has a huge influence on the initial trust [38]. Influence factors of the second type are related to firm reputation. Corporate scale and corporate image are signals of trust, which can influence consumers' initial trust [39]. Influence factors of the second type are related to the third party. Consumers can transfer trust for the third party to online suppliers. For example, Hu et al. [40] argued that web assurance seals, such as VeriSign and TRUSTe, can influence the initial trust. Similar to online trade, mobile payment also involves a high uncertainty and risk [41]. Initial trust shows users' initial understanding and judgment of new information technologies or products, which can decide users' follow-up use behaviors, and is critical to the future establishment of bilateral trust [42]. Therefore, initial trust is crucial to behaviors of mobile commerce users, which has been substantiated by some scholars. Zhou [43] held that initial trust can exert a great impact on users' acceptance of mobile banks. The perceived usefulness and perceived ease of use of TAM are deciding factors of online initial trust [44].

\subsection{TTF, UTAUT2, ITM}

UTAUT2, which is developed on the basis of personal psychology and behaviors, and good at analyzing user psychological characteristics and attitudes, can well measure users' behavioral intention [31]. Currently, it has found wide applications in the field of mobile payment, but this model has ignored external factors. For example, it does not examine the task technology fit concerning the influence of the information system on users [45]. On the contrary, TTF proceeds from the external factors to study technology characteristics and task characteristics, which can, to some extent, make up the external factors ignored by UTATU2, and recognizes the influence of external factors on humans [46]. But TTF cannot reflect the internal mechanism through which the task technology fit functions on personal behaviors, and has ignored the behavioral attitude and behavioral intention [47]. Therefore, the two models, UTAUT2 and TTF, both have certain explanatory ability, but they also have shortages, respectively [48].

Acceptance of mobile commerce is different from acceptance of information technology. Even if users do not accept information technology, users might still use the information technology when the information technology could improve personal performance [49]. Acceptance of mobile payment is subject to the influence of individual subjective factors, which should integrate UTAUT2 and TTF so that acceptance of mobile payment can be more effectively studied [48]. However, to study users' behavioral intention from the perspective of users' perception of technology, and the fit degree between technology and user tasks is not alone, but to mobile payment users, the most sensitive issues are personal information and property protection [50]. Since mobile payment involves personal financial 
information, initial trust is an important factor influencing users' acceptance of mobile payment in the initial acceptance stage of mobile payment [51].

In fact, there has been literature certifying the feasibility and validity of the integrating model in the field of mobile commerce. Tian et al. [52] held that the integrating model, compared with UTAUT2 and TAM or TTF alone, is more consistent with objective facts in the field of mobile commerce. Wu and Lee [48] also proved that the integration between UTAUT2 and TTF can well explain the use intention of third-party mobile payment users. Table 1 lists several studies that empirically verified the UTAUT, TTF, and ITM in several contexts of IS usage.

Table 1. Empirical studies using UTAUT, TTF, and ITM.

\begin{tabular}{|c|c|c|c|c|c|}
\hline Study Field & UTAUT & ITM & TTF & Other Dimensions & Authors \\
\hline Mobile shopping & $\sqrt{ }$ & & & $\begin{array}{l}\text { Innovativeness, relationship drivers, } \\
\text { skillfulness, enjoyment, anxiety }\end{array}$ & Saprikis et al. [9] \\
\hline Mobile fingerprint payment & $\sqrt{ }$ & & & $\begin{array}{l}\text { Compatibility, relative advantage, } \\
\text { perceived security }\end{array}$ & Wu and Lee [21] \\
\hline NFC mobile payment & $\sqrt{ }$ & & & $\begin{array}{l}\text { General privacy, system-related privacy, } \\
\text { perceived security }\end{array}$ & $\begin{array}{l}\text { Morosan and } \\
\text { DeFranco [32] }\end{array}$ \\
\hline Online auction & $\sqrt{ }$ & & $\sqrt{ }$ & Perceived playfulness, perceived risk & Chang [45] \\
\hline Third-party payment & $\sqrt{ }$ & & $\sqrt{ }$ & Perceived security & $\mathrm{Wu}$ and Lee [48] \\
\hline MOOCs & $\sqrt{ }$ & & $\sqrt{ }$ & MOOCs features, social motivations & Wu and Chen [49] \\
\hline Mobile banking & $\sqrt{ }$ & & $\sqrt{ }$ & - & Zhou et al. [50] \\
\hline Mobile travel & $\sqrt{ }$ & $\sqrt{ }$ & & $\begin{array}{l}\text { System quality, information quality, } \\
\text { satisfaction }\end{array}$ & Wu and Lee [53] \\
\hline Mobile banking & & $\sqrt{ }$ & & $\begin{array}{l}\text { Information quality, system quality, } \\
\text { perceived usefulness }\end{array}$ & Zhou [54] \\
\hline E-Commerce & & $\sqrt{ }$ & & Ability integrity, benevolence & $\begin{array}{c}\text { Brengman and } \\
\text { Karimov [55] }\end{array}$ \\
\hline Internet banking & & $\sqrt{ }$ & & Relative benefits, government support & Susanto et al. [56] \\
\hline Mobile banking & & $\sqrt{ }$ & & Perceived benefits & Kim et al. [57] \\
\hline Delay tolerant network & & $\sqrt{ }$ & & Distributing malicious, false public keys & $\begin{array}{l}\text { Djamaludin et al. } \\
\text { [58] }\end{array}$ \\
\hline E-Tailers & & $\sqrt{ }$ & & $\begin{array}{l}\text { Result demonstrability, assurance } \\
\text { perception }\end{array}$ & Yang et al. [59] \\
\hline mHealth & $\sqrt{ }$ & & & Technology anxiety, resistance to change & $\begin{array}{l}\text { Hoque and Sorwar } \\
{[60]}\end{array}$ \\
\hline Water purification systems & $\sqrt{ }$ & & & Physical support & Lee et al. [61] \\
\hline Mobile payment & $\sqrt{ }$ & & & $\begin{array}{l}\text { Compatibility, innovativeness, perceived } \\
\text { technology security, recommend }\end{array}$ & Oliveira et al. [62] \\
\hline
\end{tabular}

\section{Research Model and Research Hypotheses}

\subsection{Research Model}

The cross-border mobile payment use intention model is built on three mature theories, namely TTF, UTAUT2, and ITM, to gain a better understanding of the correlation of perception of mobile payment and initial trust of Chinese tourists traveling to South Korea with the task technology fit. This can promote the current knowledge system about the cross-border mobile payment use intention. The research model is depicted in Figure 1. 


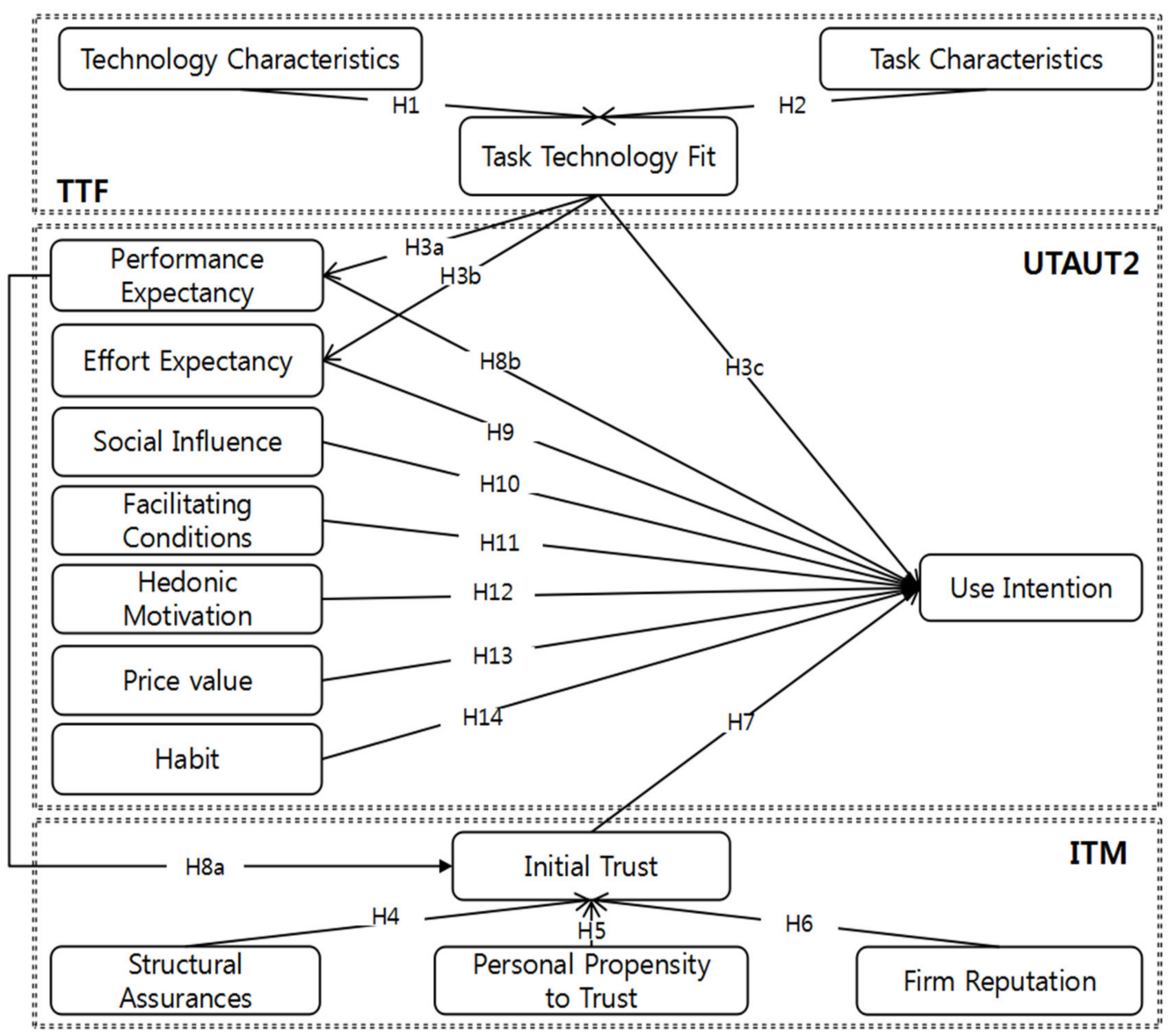

Figure 1. Research model.

\subsection{Based on the Research Hypotheses of TTF Model}

Literature review shows that research into mobile commerce is mainly based on TAM and UTAUT, with the focus on analyzing users' behavioral intention via users' perception of technology. However, to study users' behavioral intention from the perspective of users' perception of mobile payment is not yet enough. Attention should also be paid to the fit degree between technology and user task. Since acceptance of mobile payment involves fund payment, initial trust is critical to acceptance of mobile payment.

Hypothesis 1 (H1). Technology characteristics positively affect task technology fit.

Hypothesis 2 (H2). Task characteristics positively affect task technology fit.

TTF is an important theory to discuss the information technology performance, and functions of information technology, only when designed for specific tasks, can fully satisfy user demands [22]. When information technology cannot satisfy individual demands, it can reduce users' performance expectancy of the information technology [49,50]. Similarly, whether the functional design of information technology is reasonable can influence users' effort expectancy of the information technology. In other words, only when the information technology is fully matched with the task can the information technology be the best.

Therefore, only when users' tasks can be completed by mobile payment can mobile payment give full play to its advantages, thus improving users' performance expectancy. At the same time, mobile payment, compared with traditional payment modes, has a great edge over information exchange and social communication in terms of technological advancement. The advantages of mobile payment can greatly facilitate users' payment activities. All this will influence users' effort expectancy. Wu and Lee [48] believed that 
task technology fit can influence users' performance expectancy, effort expectancy, and use intention.

Hypothesis 3a (H3a). Task technology fit positively affects performance expectancy.

Hypothesis $\mathbf{3 b} \mathbf{( H 3 b ) . ~ T a s k ~ t e c h n o l o g y ~ f i t ~ p o s i t i v e l y ~ a f f e c t s ~ e f f o r t ~ e x p e c t a n c y . ~}$

Favorable task technology fit can boost the intention of Chinese visiting South Korea to use cross-border mobile payment. On the contrary, the intention of Chinese tourists to South Korea to use cross-border mobile payment will be impeded. For example, even if mobile payment is instantaneous and mobile, users will still choose the traditional payment mode when they do not have the need for mobile payment. On that basis, the following hypothesis is made:

Hypothesis 3c (H3c). Task technology fit positively affects use intention.

\subsection{Based on the Research Hypotheses of ITM Model}

Trust is believed to be an important factor deciding stable social relations, and its influence on interpersonal relationship constitutes an important part of economic transactions [63]. Structural assurances in the trust mechanism refers to the environmental and safety guarantee that can promote successful transactions, such as laws, regulations, policies, agreements, etc. [64]. Users are more likely to develop a good impression of an information technology under a safe and reliable environment [21]. Therefore, cross-border mobile payment should provide a reliable security guarantee to facilitate users' formation of initial trust.

As an international mode of mobile payment, cross-border mobile payment cannot avoid risks, which has aroused users' concern. Chinese tourists to South Korea lacking the experience in overseas use might be unwilling to use mobile payment abroad. Structural assurances, including information protection, trust services, transaction confidentiality, and contract terms can establish Chinese tourists' initial trust and confidence for and in cross-border mobile payment. Thereby, the following hypothesis is made.

Hypothesis 4 (H4). Structural assurances positively affect initial trust.

Propensity to trust is a personal trait, and a natural tendency to trust others due to the long-term influence of a person's life background [52,53]. Hence, people with a high propensity to trust are more likely to trust cross-border mobile payment.

Hypothesis 5 (H5). Personal propensity positively affects initial trust.

Firm reputation refers to individual's recognition of a film's products or services [52,53]. A firm with a good reputation can be more likely to establish user confidence, and users are more likely to develop trust for a firm with a good reputation [54].

Firm reputation is critical to the formation process of confidence and trust [55], which can strengthen users' recognition of new services and contribute to users' confidence in future transaction [56]. Hence, firm reputation constitutes an important factor for generation of initial trust among users.

Hypothesis 6 (H6). Firm reputation positively affects initial trust.

Research has shown that trust can alleviate perceived risk and encourage user behavior $[60,61]$, and strengthen users' behavioral intention $[57,58]$.

Performance expectancy, which is thought to be similar to perceived usefulness, is an important factor deciding initial trust and behavioral intention [59]. When users perceive that a certain information system is useful for themselves and helps them better finish 
certain tasks, users will develop a good impression on the information system and generate initial trust for it [43]. Similarly, when mobile payment can help Chinese visiting South Korea improve efficiency, initial trust for mobile payment can be formed. Thereby, the following hypotheses are made.

Hypothesis 7 (H7). Initial trust positively affects use intention.

Hypothesis 8a (H8a). Performance expectancy positively affects initial trust.

\subsection{Based on the Research Hypotheses of UTAUT2 Model}

Performance expectancy means to what degree users believe that acceptance of an information system can improve work performance [30,31]. This research defines performance expectancy as Chinese tourists to South Korea subjectively thinking that crossborder use of mobile payment can help improve payment efficiency, thus strengthening user intention to buy certain products or services. Therefore, this research thinks that, the more helpful the cross-border mobile payment is to Chinese traveling to South Korea, the stronger the intention of these tourists is to use cross-border mobile payment. If Chinese tourists visiting South Korea achieve payment experience via cross-border mobile payment that is better than traditional payment modes, then they might have the expectancy to use cross-border mobile payment again in their cross-border consumption, which is beneficial for sustainable development of mobile payment enterprises in the overseas market. Hence, the following hypotheses are made.

Hypothesis $\mathbf{8 b} \mathbf{( H 8 b ) . ~ P e r f o r m a n c e ~ e x p e c t a n c y ~ p o s i t i v e l y ~ a f f e c t s ~ u s e ~ i n t e n t i o n . ~}$

Effort expectancy is similar to perceived ease of use, which can reflect users' perceived difficulty of the information system and exert a positive influence on behavioral intention [30,31]. If cross-border mobile payment service procedures are easy, people will be more willing to try it. Otherwise, if users think cross-border mobile payment is hard to use or requires a great deal of effort, then expansion or maintenance of the cross-border mobile payment sustainability will be more challenging. Thus, this research thinks that cross-border mobile payment, if designing its interface, content, and functions specially for overseas users, can affect users' use intention positively.

Hypothesis 9 (H9). Effort expectancy positively affects use intention.

Social influence is similar to the subjective scale in the Theory of Reasoned Action (TRA), which can reflect the influence of external factors on user behaviors [30,31]. Since humans are social animals, human behaviors are, to a large extent, influenced by others, particularly people close to them, and the characteristics of information technology acceptance can be regarded as social influence [60]. If people around actively recommend cross-border mobile payment, users will have the idea to use cross-border mobile payment even if there are great inconveniences facing users to use cross-border mobile payment. In contrast, even if users have the intention to use cross-border mobile payment, if relatives, friends, and colleagues of users deny mobile payment, users might refer to the opinions of the public, deny their use intention, and give up using cross-border mobile payment. Zhang and Lee [65] also pointed out in their research into mobile payment that social influence can significantly influence users' use intention of mobile payment.

Hypothesis 10 (H10). Social influence positively affects use intention.

Current organizational and technological devices can play an important role in users' acceptance of information system [30,31]. Mobile payment is a kind of technological application, so ordinary users need certain skills and devices, including mobile surfing configurations and operations, to operate mobile payment [66]. To Chinese traveling to 
South Korea, they mostly hope there can be professional guidance for their use of crossborder mobile payment. When users find they have the ability to use cross-border mobile payment or can obtain some help for their use, the use intention of cross-border mobile payment will be stronger. Therefore, this research puts forward the following hypothesis:

Hypothesis 11 (H11). Facilitating conditions positively affects use intention.

With the development of mobile terminals, the entertainment functions of smartphones have been increasingly connected with the public life. An increasing number of mobile applications have been designed more and more to entertain users. Users, apart from perceiving usefulness and ease of use of mobile payment, will find mobile payment is interesting. Morosan and DeFranco [32] thought that hedonic motivation could directly influence consumers' use intention of mobile payment. As promoters of financial transactions of new forms, mobile payment is pleasant to users, which can be easily accepted [48]. Therefore, hedonic motivation is a critical factor affecting users' acceptance of cross-border mobile payment.

Hypothesis 12 (H12). Hedonic motivation positively affects use intention.

Price value refers to consumers' measurement of perceived gain and perceived cost [31]. The consumer behavior is targeted at realizing a certain expectancy, and the expectancy originates from the previously-formed consumption cognition [66]. Therefore, if relevant experiential cognition is lacking in the process of consumption, users' acceptance degree will drop [48]. In using mobile payment, users need to cover some fees, such as communication fees and transaction fees. These fees are usually higher abroad, which might hold users back from accepting mobile payment services. Oliveira et al. [62] thought that price value could positively affect use intention of mobile payment.

Hypothesis 13 (H13). Price value positively affects use intention.

A habit is an inertia formed in the long term and is hard to change, which can profoundly influence user behaviors [2]. In fact, consumers should take a series of repeated procedures from demand recognition to product consumption, and these steps might form habits under the background of mobile commerce [67,68]. Chinese travelers' repeated use of mobile payment in China will strengthen users' use intention of mobile payment overseas. Morosan and DeFranco [32] thought that habit could directly influence consumers' use intention of NFC mobile payment.

Hypothesis 14 (H14). Habit positively affects use intention.

\section{Method}

The questionnaire started from 1 July 2020 to 1 October 2020. Chinese tourists using mobile payment in South Korea were chosen as respondents. There were 889 copies of questionnaires collected via https:/ / www.wjx.cn/ (accessed on 1 July 2020 to 1 October 2020). The study's measurement items refer to Appendix A. In order to guarantee validity of the questionnaire, the valid copies of the questionnaire were screened out, with 103 copies of questionnaire that were invalid and dishonest deletes. In order to ensure the validity and integrity of the questionnaire, we first eliminated those with questions unfilled. We defined questionnaires with $70 \%$ of the questions answered with the same number as invalid samples. Questionnaires with an obvious answering rule (such as 1, 2, 3, 4, 1, 2, 3, 4) were also deemed as invalid. Finally, 786 copies of the valid questionnaire were collected, representing a valid response rate of $88.4 \%$. The data obtained from the questionnaire are analyzed below using IBM SPSS v23.0 (Armonk, NY, USA) and IBM AMOS v23.0 (Armonk, NY, USA). 
Below is the demographic analysis. From the gender perspective, there are 357 males, accounting for $45.4 \%$ of the total, and 429 females, accounting for $54.6 \%$ of the total. This means that the percentage of female respondents is higher than that of male counterparts. Considering the age structure, there are 32 respondents below the age of $20(4.1 \%), 189$ aged 20 years old to 29 years old (24\%), $353(44.9 \%)$ aged 30 to 39 years old, $123(15.6 \%)$ aged 40 to 49 years old, and $89(11.4 \%)$ aged above 50 years old. Among them, the percentage of the age group of 30 to 39 years old is the highest. Concerning respondents' educational degree, $66(8.4 \%)$ hold a degree below the senior high school, $175(22.3 \%)$ hold a degree of the senior high school, $475(60.4 \%)$ hold an undergraduate degree, which are the highest in percentage, and $70(8.9 \%)$ hold a master and $\mathrm{PhD}$ degree. From the occupational perspective, $52(6.6 \%)$ are students, $238(30.3 \%)$ are self-employed, $361(45.9 \%)$ are company staff, $102(13 \%)$ are public servants, and $33(4.2 \%)$ follow other professions or are jobless.

On the whole, the research samples are of different age groups, holding different academic degrees, and from different industries. These respondents are major users of cross-border mobile payment, which play an important role in explaining use intention of cross-border mobile payment. This can lay a solid foundation for follow-up research. Table 2 shows the result of demographic information.

Table 2. Demographic Information.

\begin{tabular}{cccc}
\hline \multirow{3}{*}{ Demographic Information } & Frequency & $\%$ \\
\hline \multirow{4}{*}{ Agerer } & Male & 357 & $45.4 \%$ \\
& Female & 429 & $54.6 \%$ \\
\hline \multirow{5}{*}{ Education } & Under 20 & 32 & $4.1 \%$ \\
& $20-29$ & 189 & $24 \%$ \\
& $30-39$ & 353 & $44.9 \%$ \\
& $40-49$ & 123 & $15.6 \%$ \\
& Over 50 & 89 & $11.4 \%$ \\
\hline \multirow{5}{*}{ Occupation } & Under high school & 66 & $8.4 \%$ \\
& High school & 175 & $22.3 \%$ \\
& Bachelor's Degree & 475 & $60.4 \%$ \\
& Master/Doctorate Degree & 238 & $30.3 \%$ \\
\hline & Students & 52 & $6.6 \%$ \\
& Self-employed & 238 & $30.3 \%$ \\
& Company staff & 361 & $45.9 \%$ \\
& Public servants & 102 & $13 \%$ \\
& Other & 33 & $4.2 \%$ \\
\hline
\end{tabular}

\section{Results}

\subsection{Measurement Model}

SPSS is used to carry out reliability analysis of the questionnaire. Cronbach's $\alpha$ of every variable is above 0.8 , which exceeds the general level, 0.7 . This suggests favorable reliability of the measurement model [69].

AMOS is used to conduct a convergent validity test of the questionnaire. All loadings are higher than 0.4 , and the composite reliability (CR) of every variable is higher than 0.6. Meanwhile, the average variance extracted (AVE) of every variable is larger than 0.5 , suggesting favorable validity of the measurement model [69]. Table 1 presents that the loadings of all statements exceed 0.7 , the $C R$ value of every variable is larger than 0.8 , and the AVE value is larger than 0.6 . This suggests that the 15 potential variables have favorable composite reliability and convergent validity. The questionnaire designed in this paper has favorable internal quality. Table 3 shows the result of composite reliability and con-vergent validity our measurement model. 
Table 3. Quality criteria (AVE, CR, Cronbach's $\alpha$ ) and loadings.

\begin{tabular}{|c|c|c|c|c|c|}
\hline Factor & Item & Cronbach's $\alpha$ & AVE & CR & Loading \\
\hline \multirow{3}{*}{ Technology Characteristics } & TC1 & \multirow{3}{*}{0.870} & \multirow{3}{*}{0.692} & \multirow{3}{*}{0.871} & 0.869 \\
\hline & TC2 & & & & 0.784 \\
\hline & TC3 & & & & 0.841 \\
\hline \multirow{3}{*}{ Task Characteristics } & TAC1 & \multirow{3}{*}{0.878} & \multirow{3}{*}{0.706} & \multirow{3}{*}{0.878} & 0.861 \\
\hline & TAC2 & & & & 0.797 \\
\hline & TAC3 & & & & 0.861 \\
\hline \multirow{3}{*}{ Task Technology Fit } & TTF1 & \multirow{3}{*}{0.861} & \multirow{3}{*}{0.674} & \multirow{3}{*}{0.861} & 0.822 \\
\hline & TTF2 & & & & 0.800 \\
\hline & TTF3 & & & & 0.841 \\
\hline \multirow{4}{*}{ Structural Assurances } & SA1 & \multirow{4}{*}{0.904} & \multirow{4}{*}{0.702} & \multirow{4}{*}{0.904} & 0.858 \\
\hline & SA2 & & & & 0.820 \\
\hline & SA3 & & & & 0.822 \\
\hline & SA4 & & & & 0.851 \\
\hline \multirow{4}{*}{ Personal Propensity to Trust } & PPT1 & \multirow{4}{*}{0.871} & & & 0.785 \\
\hline & PPT2 & & & & 0.796 \\
\hline & РPT3 & & 0.629 & 0.871 & 0.809 \\
\hline & PPT4 & & & & 0.781 \\
\hline & FR1 & & & & 0.783 \\
\hline Firm Reputation & FR2 & 0868 & 0.623 & 0869 & 0.803 \\
\hline & FR3 & 0.868 & & 0.869 & 0.799 \\
\hline & FR4 & & & & 0.773 \\
\hline & IT1 & & & & 0.816 \\
\hline & IT2 & & & & 0.787 \\
\hline Initial Trust & IT3 & 0.869 & 0.623 & 0.869 & 0.755 \\
\hline & IT4 & & & & 0.798 \\
\hline & PE1 & & & & 0.771 \\
\hline Performance Expectancy & PE2 & 0866 & 0618 & 0866 & 0.778 \\
\hline & PE3 & 0.866 & 0.618 & 0.866 & 0.790 \\
\hline & PE4 & & & & 0.805 \\
\hline & EE1 & & & & 0.809 \\
\hline & EE2 & & & & 0.804 \\
\hline Effort Expectancy & EE3 & 0.881 & 0.650 & 0.881 & 0.767 \\
\hline & EE4 & & & & 0.843 \\
\hline & SI1 & & & & 0.818 \\
\hline Social Inflyence & SI2 & 0881 & 0651 & 0882 & 0.789 \\
\hline Social Influence & SI3 & 0.881 & & 0.882 & 0.783 \\
\hline & SI 4 & & & & 0.836 \\
\hline & FC1 & & & & 0.754 \\
\hline & FC2 & & & & 0.779 \\
\hline Facilitating Conditions & FC3 & 0.863 & 0.613 & 0.864 & 0.781 \\
\hline & FC4 & & & & 0.817 \\
\hline & HM1 & & & & 0.827 \\
\hline Hedonic Motivation & HM2 & 0887 & 0663 & 0887 & 0.810 \\
\hline Hedonic Motivation & HM3 & 0.887 & 0.663 & 0.887 & 0.790 \\
\hline & HM4 & & & & 0.829 \\
\hline & PV1 & & & & 0.830 \\
\hline Price Value & PV2 & 0.836 & 0.637 & 0.840 & 0.727 \\
\hline & PV3 & & & & 0.832 \\
\hline & HA1 & & & & 0.831 \\
\hline & HA2 & & & & 0.820 \\
\hline Habit & HA3 & 0.891 & 0.673 & 0.892 & 0.826 \\
\hline & HA4 & & & & 0.804 \\
\hline & UI1 & & & & 0.775 \\
\hline Use Intention & UI2 & 0.862 & 0.610 & 0.862 & 0.790 \\
\hline Use intention & UI3 & 0.862 & 0.010 & 0.002 & 0.787 \\
\hline & UI4 & & & & 0.772 \\
\hline
\end{tabular}

Table 4 is a summary of correlation coefficients among 15 latent variables. The number on the diagonal line is the square root (in bold numbers) of every variable's AVE. The square root of AVE of every variable falls between 0.781 and 0.944 . The absolute value of 
the correlation efficient between different variables is smaller than 0.6. The square root of the AVE of every variable is obviously larger than the correlation coefficient between the variable and other variables. This suggests favorable discriminant validity among the 15 latent variables.

Table 4. Fornell-Larcker criterion discriminant validity (in bold numbers).

\begin{tabular}{|c|c|c|c|c|c|c|c|c|c|c|c|c|c|c|c|}
\hline & TC & TAC & TTF & SA & PPT & FR & IT & PE & EE & SI & FC & HM & PV & HA & UI \\
\hline $\mathrm{TC}$ & 0.832 & & & & & & & & & & & & & & \\
\hline TAC & 0.553 & 0.840 & & & & & & & & & & & & & \\
\hline TTF & 0.203 & 0.212 & 0.821 & & & & & & & & & & & & \\
\hline SA & 0.154 & 0.226 & 0.174 & 0.838 & & & & & & & & & & & \\
\hline PPT & 0.383 & 0.360 & 0.192 & 0.214 & 0.793 & & & & & & & & & & \\
\hline FR & 0.043 & 0.063 & 0.064 & -0.041 & 0.297 & 0.789 & & & & & & & & & \\
\hline IT & 0.367 & 0.378 & 0.247 & 0.236 & 0.656 & 0.213 & 0.789 & & & & & & & & \\
\hline PE & -0.001 & 0.011 & 0.106 & -0.065 & 0.034 & 0.069 & 0.148 & 0.786 & & & & & & & \\
\hline $\mathrm{EE}$ & 0.039 & -0.024 & 0.083 & -0.037 & -0.018 & 0.027 & 0.032 & 0.052 & 0.806 & & & & & & \\
\hline SI & -0.051 & -0.131 & -0.121 & -0.027 & 0.024 & 0.010 & 0.052 & 0.075 & 0.296 & 0.807 & & & & & \\
\hline FC & -0.158 & -0.175 & -0.062 & 0.004 & 0.082 & 0.078 & 0.034 & 0.020 & 0.218 & 0.462 & 0.783 & & & & \\
\hline $\mathrm{HM}$ & -0.137 & -0.119 & 0.013 & 0.061 & 0.064 & 0.006 & 0.027 & -0.015 & 0.089 & 0.231 & 0.257 & 0.942 & & & \\
\hline PV & 0.020 & -0.005 & 0.065 & 0.269 & 0.043 & 0.096 & 0.039 & 0.018 & 0.058 & 0.042 & 0.230 & 0.157 & 0.917 & & \\
\hline HA & -0.101 & -0.030 & -0.030 & 0.030 & 0.108 & 0.039 & 0.104 & -0.005 & 0.116 & 0.231 & 0.354 & 0.411 & 0.228 & 0.944 & \\
\hline UI & 0.199 & 0.182 & 0.206 & 0.102 & 0.228 & 0.122 & 0.294 & 0.339 & 0.165 & 0.169 & 0.215 & 0.112 & 0.168 & 0.143 & 0.781 \\
\hline
\end{tabular}

Further, as presented by Voorhees et al. [70], we tested the Heterotrait-Monotrait Ratio (HTMT). If the HTMT value is below 0.85 , discriminant validity has been established between two reflective constructs. Table 5 shows the result of HTMT against our data. All the values meet the threshold.

Table 5. Heterotrait-Monotrait Ratio (HTMT).

\begin{tabular}{|c|c|c|c|c|c|c|c|c|c|c|c|c|c|c|c|}
\hline & TC & $\mathrm{TaC}$ & TTF & SA & PPT & FR & IT & PE & EE & SI & FC & HM & PV & HA & IU \\
\hline $\mathrm{TC}$ & & & & & & & & & & & & & & & \\
\hline $\mathrm{TaC}$ & 0.545 & & & & & & & & & & & & & & \\
\hline TTF & 0.199 & 0.214 & & & & & & & & & & & & & \\
\hline SA & 0.152 & 0.219 & 0.173 & & & & & & & & & & & & \\
\hline PPT & 0.375 & 0.358 & 0.191 & 0.215 & & & & & & & & & & & \\
\hline FR & 0.044 & 0.061 & 0.070 & 0.047 & 0.297 & & & & & & & & & & \\
\hline IT & 0.358 & 0.375 & 0.244 & 0.236 & 0.655 & 0.212 & & & & & & & & & \\
\hline $\mathrm{PE}$ & 0.039 & 0.014 & 0.109 & 0.065 & 0.044 & 0.070 & 0.151 & & & & & & & & \\
\hline $\mathrm{EE}$ & 0.052 & 0.039 & 0.086 & 0.036 & 0.053 & 0.037 & 0.050 & 0.058 & & & & & & & \\
\hline SI & 0.051 & 0.124 & 0.123 & 0.034 & 0.037 & 0.038 & 0.061 & 0.079 & 0.295 & & & & & & \\
\hline $\mathrm{FC}$ & 0.166 & 0.178 & 0.062 & 0.031 & 0.083 & 0.075 & 0.052 & 0.030 & 0.221 & 0.465 & & & & & \\
\hline $\mathrm{HM}$ & 0.137 & 0.117 & 0.038 & 0.058 & 0.065 & 0.034 & 0.035 & 0.031 & 0.090 & 0.232 & 0.258 & & & & \\
\hline PV & 0.034 & 0.018 & 0.059 & 0.273 & 0.055 & 0.099 & 0.048 & 0.035 & 0.055 & 0.053 & 0.235 & 0.165 & & & \\
\hline HA & 0.106 & 0.032 & 0.043 & 0.048 & 0.109 & 0.046 & 0.106 & 0.030 & 0.114 & 0.234 & 0.357 & 0.411 & 0.231 & & \\
\hline IU & 0.196 & 0.184 & 0.206 & 0.101 & 0.226 & 0.121 & 0.296 & 0.341 & 0.168 & 0.169 & 0.216 & 0.111 & 0.167 & 0.142 & \\
\hline
\end{tabular}

Table 6 shows that by excluding the NFI and GFI values, which are slightly smaller than the recommended value, the value of the rest of the fit indexes is superior to the recommended value. This indicates a favorable degree of fitting of the model, and that the model is acceptable.

Table 6. The recommended values and actual values of fit indices.

\begin{tabular}{ccccccccc}
\hline Model Fit Indices & $\chi^{2} / \mathbf{D F}$ & NFI & CFI & GFI & TLI & AGFI & RMR & RMSEA \\
\hline Recommended value & $<3$ & $>0.90$ & $>0.90$ & $>0.90$ & $>0.90$ & $>0.80$ & $<0.10$ & $<0.08$ \\
Structural model & 1.903 & 0.896 & 0.948 & 0.893 & 0.943 & 0.879 & 0.038 & 0.034 \\
\hline
\end{tabular}




\subsection{Hypothesis Analysis}

From the above analysis, one can see that data of this research possess high reliability and validity. The model also passes the fitting test. Therefore, when AMOS is used for path analysis, no model modification is required. Only the model setting and data input are required to work out the results. The path coefficient and verification results of hypotheses made in this research are shown in Table 7 below:

Table 7. Hypothesis testing.

\begin{tabular}{|c|c|c|c|c|c|c|}
\hline & Hypothesis & Path Coefficient & S.E. & C.R. & $p$-Value & Results \\
\hline $\mathrm{H} 1$ & Technology Characteristics $\rightarrow$ Task Technology Fit & 0.109 & 0.044 & 2.474 & 0.013 & Supported \\
\hline $\mathrm{H} 2$ & Task Characteristics $\rightarrow$ Task Technology Fit & 0.135 & 0.045 & 2.991 & 0.003 & Supported \\
\hline Н3а & Task Technology Fit $\rightarrow$ Performance Expectancy & 0.096 & 0.036 & 2.268 & 0.001 & Supported \\
\hline $\mathrm{H} 3 \mathrm{~b}$ & Task Technology Fit $\rightarrow$ Effort Expectancy & 0.079 & 0.039 & 2.037 & 0.042 & Supported \\
\hline $\mathrm{H} 3 \mathrm{c}$ & Task Technology Fit $\rightarrow$ Use Intention & 0.117 & 0.033 & 3.525 & $* * *$ & Supported \\
\hline $\mathrm{H} 4$ & Structural Assurances $\rightarrow$ Initial Trust & 0.091 & 0.036 & 2.643 & 0.008 & Supported \\
\hline H5 & Personal Propensity to Trust $\rightarrow$ Initial Trust & 0.663 & 0.045 & 14.771 & $* * *$ & Supported \\
\hline H6 & Firm Reputation $\rightarrow$ Initial Trust & 0.022 & 0.039 & 0.567 & 0.570 & Not supported \\
\hline $\mathrm{H} 7$ & Initial Trust $\rightarrow$ Use Intention & 0.193 & 0.035 & 5.525 & $* * *$ & Supported \\
\hline H8a & Performance Expectancy $\rightarrow$ Initial Trust & 0.146 & 0.036 & 4.050 & $* * *$ & Supported \\
\hline $\mathrm{H} 8 \mathrm{~b}$ & Performance Expectancy $\rightarrow$ Use Intention & 0.280 & 0.039 & 7.133 & $* * *$ & Supported \\
\hline H9 & Effort Expectancy $\rightarrow$ Use Intention & 0.078 & 0.034 & 2.279 & 0.023 & Supported \\
\hline H10 & Social Influence $\rightarrow$ Use Intention & 0.053 & 0.039 & 1.375 & 0.169 & Not supported \\
\hline H11 & Facilitating Conditions $\rightarrow$ Use Intention & 0.126 & 0.048 & 2.625 & 0.009 & Supported \\
\hline $\mathrm{H} 12$ & Hedonic Motivation $\rightarrow$ Use Intention & 0.022 & 0.034 & 0.647 & 0.518 & Not supported \\
\hline H13 & Price Value $\rightarrow$ Use Intention & 0.097 & 0.037 & 2.614 & 0.009 & Supported \\
\hline H14 & Habit $\rightarrow$ Use Intention & 0.021 & 0.035 & 0.600 & 0.549 & Not supported \\
\hline
\end{tabular}

\section{Discussion}

In this research, the questionnaire is designed to verify the validity of the integrated model of TTF, ITM, and UTAUT2. The integrated model can explain cross-border mobile payment users' use intention. Results show that all hypotheses revolving around the TTF model have been substantiated by data. Technology characteristics $(\beta=0.109)$ and task characteristics ( $\beta=0.135$ ) can both influence the task technology fit significantly. The task technology fit can exert a significant influence on the performance expectancy $(\beta=0.096)$, effort expectancy $(\beta=0.079)$, and use intention $(\beta=0.117)$. These results are consistent with those of previous research findings [48], which can not only cast light on the correlation between the TTF model and the UTAUT2 model, but also verify that, when services provided by cross-border mobile payment can satisfy consumer demands of Chinese traveling to South Korea, users will think it is useful and easy to use, which will directly influence users' use intention. In this way, users will think it is useful and easy to use, which will directly influence users' use intention. Therefore, mobile payment enterprises, in promoting overseas payment, should consider the fit between users' task demands and cross-border mobile payment functions. For example, Chinese tourists might consume in different places of South Korea (such as hotels and duty-free stores). This requires cross-border mobile payment to satisfy users' need to make payments at different periods of time and in different places abroad.

As to hypotheses made about the ITM, all the hypotheses excluding firm reputation gain the data support. Performance expectancy $(\beta=0.146)$, structural assurances $(\beta=0.091)$, and personal propensity to trust $(\beta=0.663)$ can all significantly influence the initial trust. In turn, the initial trust $(\beta=0.193)$ can significantly influence the use intention. These results are consistent with those of previous research [53] and suggest the correlation between the ITM and the UTAUT2. Meanwhile, the influence of the personal propensity to trust on the initial trust is the strongest. This means that users with the propensity to trust will more easily have the initial trust for the cross-border mobile payment. When Chinese 
tourists think that mobile payment is useful and can guard against risks in South Korea, they are more willing to use the cross-border mobile payment existing as a new service. Research also shows that the firm reputation will not significantly influence the initial trust, as previously reported in other studies [52]. This suggests that users do not care about whether mobile payment enterprises have a high reputation abroad. Under the condition of risk guarantee and performance optimization, Chinese tourists might be more interested in cross-border mobile payment.

As to hypotheses made about UTAUT2, the performance expectancy $(\beta=0.28)$ can significantly influence the use intention. Specifically, the performance expectancy has the strongest influence on the use intention. Besides, TTF can influence the use intention via the performance expectancy. At the same time, the performance expectancy can influence the use intention via the initial trust $[48,53]$. This can not only prove the correlation among ITM, TTF, and UTAUT2, but also provide solid evidence for the importance of the performance expectancy. To what extent that cross-border mobile payment can increase efficiency of consumer behaviors of Chinese tourists is of vital importance to study the use intention of cross-border mobile payment. Research results also suggest that the effort expectancy $(\beta=0.078)$, facilitating conditions $(\beta=0.126)$, and price value $(\beta=0.097)$ can significantly influence the use intention. First of all, when Chinese users are using cross-border mobile payment in South Korea, they can obtain technical support and service support. If cross-border mobile payment requires little effort to operate, users will be more willing to use it. Second, the fees generated by users' use of cross-border mobile payment in South Korea are also one of the major considerations for Chinese consumers to decide whether to use cross-border mobile payment or not. However, the social influence ( $\beta=0.053)$ on the use intention is insignificant. This means that suggestions provided by people around users actually cannot stimulate users' desire to use cross-border mobile payment. This is probably because cross-border mobile payment is a highly sensitive personal financial service. Chinese tourists' requirement to keep the financial data and transaction in confidentiality has covered their need of ostentatious consumption. Hedonic motivation $(\beta=0.022)$ and habit $(\beta=0.021)$ cannot significantly predict the use intention of cross-border mobile payment. Thus, the following conclusion can be reached, that is, hedonic motivation and habit in the new structure of UTAUT2 are not correlated with the cross-border mobile payment use intention.

\section{Implications}

This research has made several major theoretical contributions. First, this research extends the research into mobile payment from a novel perspective. As far as we are concerned, the early research, though having already involved the applications of mobile payment, has not yet examined the use intention of cross-border mobile payment. Therefore, this research concentrates on the use intention of cross-border mobile payment, which can make precious contributions to the extension of the research scope of mobile payment. Second, this research explains the use intention of cross-border mobile payment using integrated research methods, and emphasizes the correlation among the UTAUT2, ITM, and TTF. Though previous research findings have already indicated a significantly direct influence of performance expectancy on the use intention, few research findings have shed light on the mediating variable between the performance expectancy and the use intention. PE can exert an influence on the use intention via the initial trust. Meanwhile, TTF is one of major prerequisites for the generation of performance expectancy among users. All these research findings will deepen the understanding of the use intention of cross-border mobile payment and lay a solid foundation for sustainable research into the future cross-border mobile payment field.

Our results also have implications for practitioners. Conclusions of this research can provide practical implications for cross-border mobile payment use intention, facilitate cross-border mobile payment institutions' optimization of their services and implementation, and attract potential Chinese users and boost consumption. To identify which 
factors can affect consumers' cross-border mobile payment, use intention is necessary. Under the background of rapid growth of information technology and global integration, a comprehensive viewpoint can contribute to sustainability of this research, and provide the theoretical basis for the expansion of the future research scope to the world scale. Considering that Chinese are the largest number of tourists traveling to South Korea, the tourists are adopted as research objects. By analyzing which factors can promote crossborder mobile payment use intention, this paper attempts to motivate core influencing factors of cross-border mobile payment in South Korea, and provide a necessary theoretical basis and practical preparation for sustainable cooperation between the large-scale Fintech market and tourist consumption market between China and South Korea. The variables of TTF and UTAUT2 are correlated. In other words, technology characteristics can significantly affect performance expectancy and effort expectancy. An important channel to improve users' performance expectancy is to ensure task technology fit. If users acquire payment services which are inconsistent with user demands, it is hardly predictable that the service can achieve favorable performance. This requires cross-border mobile payment to provide corresponding services according to user tasks. Additionally, netizens who surf the Internet using mobile phones mostly prefer exquisite and convenient services and content. Therefore, cross-border mobile payment enterprises should take the mobile terminals and grid limitations into consideration so as to provide consistent improvement of interface design and response rate, which can quickly acquire settlement information, facilitate users' operations and use, and increase users' effort expectancy. Particularly to some old user groups, ease of use of cross-border mobile payment is very important, and professionals can be equipped to provide guidance for senior users. Facilitating conditions can significantly affect users' intention to use cross-border mobile payment. Since the technology and environment for cross-border mobile payment are still in the initial development stage, operators, apart from continuously expanding the overseas mobile payment market, should resolve technological or service difficulties facing users in the use process of cross-border mobile payment so as to avoid the loss rate of users. Additionally, an active response should be made to these problems. Overseas technological support and after-sales service should be reinforced to not let users feel helpless abroad and also prevent users from rejecting cross-border mobile payment. Price value can significantly affect users' cross-border mobile payment use intention. Cross-border mobile payment enterprises should consider bringing down the service fees generated by Chinese tourists' use of cross-border mobile payment, and providing a reasonable exchange mechanism. Cross-border mobile payment enterprises can provide preferential activities, such as preferential coupons for Chinese tourists traveling to South Korea to increase cross-border mobile payment use intention among Chinese consumers. To improve users' initial trust for cross-border mobile payment is of vital significance. In whatever field, as long as money is involved, money is always one of the most important factors affecting user behaviors. Therefore, it is necessary to strictly control technological risks, protect security of user data, and reduce risks facing users to suffer financial losses while using cross-border mobile payment abroad. Measures, such as strengthening of the monitoring system, reinforcement of the Great Firewall, and monitoring the secret-stealing system and restoration system, can be taken to guarantee data completeness.

\section{Limitations and Future Research}

This research revolves around cross-border mobile payment use intention among Chinese tourists traveling to South Korea. In spite of the rigorousness and innovativeness of literature review, theoretical model building, and questionnaire design, this research still has the following limitations, due to constraints of human resources, material resources, and other objective conditions.

Research objects fall under the range of 20 years old to 40 years old. The major respondents are graduating from a college with a bachelor's degree. Affected by multiple factors, including difference of professions and salaries, the samples withdrawn might be 
unable to reflect the overall situations. Therefore, it is necessary to expand the age scope of research objects and include more research objects.

According to UTAUT2, TTF, and ITM, this research proposes the following hypotheses. But there are still potential influencing factors to be developed. The future research can proceed from different theoretical perspectives to put forward more diverse hypotheses and influencing factors so that the formulation of strategies can be completer and more accurate. With the development of the future economy and environment, applicability of UTAUT2, TTF, and ITM will be impaired. In the future, cross-border mobile payment should be investigated more.

The adjusting variables of UTAUT2 include the gender, age, experience, and voluntariness of use. Nevertheless, the samples are seriously disproportionate in terms of their age and gender. This research studies users with the use experience. At the same time, cross-border mobile payment is in itself a voluntary behavior. The non-voluntary behavior is rare to see. So, these four adjusting variables are not examined. The follow-up research can introduce these adjusting variables for further discussions.

\section{Conclusions}

This research focuses on studying cross-border mobile payment, which is not only an innovative technology, but also an innovative service. As a substitute of the cash or credit card, cross-border mobile payment has gained growing attention. Pitifully, existing literature related to mobile payment has not yet deeply discussed the concept of the crossborder mobile payment behavior and user intention. In order to make up the research gap, this research proposes an integrated model and empirically verifies it to explain the user decision to adopt cross-border mobile payment. Through a test of the research model based on the sample data of South Korean and Chinese tourists, this research identifies major antecedents that can affect user adoption, and enriches the knowledge under this topic. Research results suggest that this model can explain the cross-border mobile payment user intention of Chinese tourists traveling to South Korea. The integrated model of UTUAT2, TFF, and ITM is not only appealing theoretically, but is also significant empirically, because it explains the cross-border business in mobile payment. Research reveals that task technology fit, initial trust, performance expectancy, effort expectancy, facilitating conditions, and price value are major factors that can explain the cross-border mobile payment use behaviors. Thereby, we suggest that companies related to cross-border mobile applications should take a good look at this research to gain a better understanding of what drives the user intention to use their products. To researchers, this research can lay a solid foundation for improvement of the individual adoption model.

Author Contributions: R.-Z.W. initiated and conceived the paper and writing-original draft preparation, and X.-F.T. conceived the research model, writing-review and editing. J.-H.L. performed data curation and analyzed the empirical result. All authors have read and agreed to the published version of the manuscript.

Funding: This research received no external funding.

Institutional Review Board Statement: Not applicable.

Informed Consent Statement: Not applicable.

Data Availability Statement: Not applicable.

Conflicts of Interest: The authors declare no conflict of interest. 


\section{Appendix A}

Table A1. Questionnaire.

\begin{tabular}{|c|c|}
\hline Dimensions & Texts of Items \\
\hline Technology characteristics $[47,48]$ & $\begin{array}{l}\text { Mobile payment provides ubiquitous services in Korea. } \\
\text { Mobile payment provides a real-time service in Korea. } \\
\text { Mobile payment provides a quick service in Korea. }\end{array}$ \\
\hline Task characteristics $[47,48]$ & $\begin{array}{l}\text { I need to manage my accounts anytime anywhere in Korea. } \\
\text { I need to settle accounts anytime anywhere in Korea. } \\
\text { In Korea, I need to have a real-time control in my accounts. }\end{array}$ \\
\hline Task technology fit $[47,48]$ & $\begin{array}{l}\text { Mobile payment is appropriate in Korea. } \\
\text { Mobile payment account management services are appropriate in Korea. } \\
\text { Real-time mobile payment services are suitable in Korea. }\end{array}$ \\
\hline Structural assurances $[52,53]$ & $\begin{array}{l}\text { In Korea, I do not incur the risk of financial losses using mobile payment. } \\
\text { I do not incur the risk of personal information theft using mobile payment. } \\
\text { In Korea, my mobile payment service has a Client Protection Policy. } \\
\text { My personal mobile phone information is secure when I use the mobile payment in Korea. }\end{array}$ \\
\hline Personal propensity to trust $[52,53]$ & $\begin{array}{l}\text { I like the new environment. } \\
\text { I like to use of new products like mobile payment in Korea. } \\
\text { In Korea, I like to use of non-classical means to transact money. } \\
\text { In Korea, I trust the financial transactions I execute. }\end{array}$ \\
\hline
\end{tabular}

In Korea, I trust my mobile payment.

Firm reputation $[52,53] \quad$ My mobile payment is known for its suitability in Korea.

In Korea, the services my mobile payment provides are of great quality.

In Korea, my mobile payment is a secure application.

Initial trust [52,53]

In Korea, mobile payment seems dependable.

In Korea, mobile payment seems secure.

In Korea, mobile payment seems reliable.

In Korea, mobile payment was created to help the client.

In Korea, mobile payment is useful to carry out my tasks.

Using mobile payments would increase the efficiency of shopping.

Performance expectancy $[30,48]$

Using mobile payments in Korea would improve the quality of my travel quality.

Using mobile payments would allow me to have more convenient shopping in Korea.

In Korea, it is easy to enter in the mobile payment page.

My interactions with my mobile phone and transaction terminals when using mobile

Effort expectancy $[30,48]$

payment in Korea are clear and understandable.

I find it easy to use mobile payment in Korea.

It is easy for me to become skillful at using mobile payment in Korea.

My friends think that I should use mobile payments in Korea.

Social influence $[30,48]$

My family think that I should use mobile payments in Korea.

People who influence my behavior use mobile payment in Korea.

The use of mobile payment in South Korea gives me professional status.

I have all the necessary resources to use mobile payment in Korea.

I have the know-how to use mobile payment in Korea.

Facilitating conditions $[30,48] \quad$ If I have any doubts about how to use the mobile payment service in Korea, I do have a support line to help me.

Mobile payment is compatible with other technologies in Korea.

Using mobile payment in Korea is fun.

Hedonic motivation [31,48] Using mobile payment in Korea is enjoyable.

Using mobile payment in Korea is very entertaining.

Using mobile payment in Korea is pleasant. 
Table A1. Cont.

\begin{tabular}{cl}
\hline \multicolumn{1}{c}{ Dimensions } & Texts of Items \\
& Mobile payment is reasonably priced in Korea. \\
Price value $[31,48]$ & In Korea mobile payment is a good value for the money. \\
& At the current price, mobile payment provides a good value in Korea. \\
& The use of mobile payment has become a habit for me. \\
& I am addicted to using mobile phone for general payment. \\
& I must use mobile phone for payment. \\
& Using mobile payment has become natural to me. \\
& I have the intention of making a service payment by mobile phone. \\
& I have the intention of managing my accounts using my mobile phone. \\
& I have the intention of making a transfer by mobile phone. \\
Use Intention $[31,48]$ & I have the intention of making my transactions by using the mobile payment service. \\
\hline
\end{tabular}

Note: All items are based on 5-point scale (5 being "strongly agree" and 1 being "strongly disagree").

\section{References}

1. Lin, X.; Wu, R.; Lim, Y.-T.; Han, J.; Chen, S.-C. Understanding the Sustainable Usage Intention of Mobile Payment Technology in Korea: Cross-Countries Comparison of Chinese and Korean Users. Sustainability 2019, 11, 5532. [CrossRef]

2. Gong, X.; Zhang, K.Z.K.; Chen, C.; Cheung, C.M.K.; Lee, M.K.O. Transition from web to mobile payment services: The triple effects of status quo inertia. Int. J. Inform. Manag. 2020, 50, 310-324. [CrossRef]

3. Son, I.; Kim, S. Mobile payment service and the firm value: Focusing on both up- and Down-Stream Alliance. Sustainability 2018, 10, 2583. [CrossRef]

4. Liao, Y.; He, Y.; Li, F.; Zhou, S. Analysis of a mobile payment protocol with outsourced verification in cloud server and the improvement. Comput. Stand. Interfaces 2018, 56, 101-106. [CrossRef]

5. Song, M.K.; Kim, S.H. A study on the difference of medical tourism storytelling attributes by the medical tourists' behavior characteristic and demographic characteristic: Focused on Chinese and Japanese medical tourist in Korea. Int. J. Tourism Manag. Sci. 2016, 31, 43-68.

6. Kim, D.; Kim, Y. Empirical analysis on the influential factors of the frequency of visit by Chines foreign independent traveler visiting Korea by ordered probit model. Int. J. Tour. Manag. Sci. 2018, 33, 1-14.

7. Fan, L.; Zhang, X.; Rai, L.; Du, Y. Mobile Payment: The Next Frontier of Payment Systems? An Empirical Study Based on Push-Pull-Mooring Framework. J. Theor. Appl. Electron. Commer. Res. 2021, 16, 155-169. [CrossRef]

8. Karsen, M.; Chandra, Y.U.; Juwitasary, H. Technological factors of mobile payment: A systematic literature review. Procedia Comput. Sci. 2019, 157, 489-498. [CrossRef]

9. Saprikis, V.; Markos, A.; Zarmpou, T.; Vlachopoulou, M. Mobile Shopping Consumers' Behavior: An Exploratory Study and Review. J. Theor. Appl. Electron. Commer. Res. 2018, 13, 71-90. [CrossRef]

10. Molina-Castillo, F.-J.; Lopez-Nicolas, C.; de Reuver, M. Mobile Payment: The Hiding Impact of Learning Costs on User Intentions. J. Theor. Appl. Electron. Commer. Res. 2020, 15, 1-12. [CrossRef]

11. Wei, M.-F.; Luh, Y.-H.; Huang, Y.-H.; Chang, Y.-C. Young Generation's Mobile Payment Adoption Behavior: Analysis Based on an Extended UTAUT Model. J. Theor. Appl. Electron. Commer. Res. 2021, 16, 618-637. [CrossRef]

12. Yang, S.; Lu, Y.; Gupta, S.; Cao, Y.; Zhang, R. Mobile payment services adoption across time: An empirical study of the effects of behavioral beliefs, social influences, and personal traits. Comput. Hum. Behav. 2012, 28, 129-142. [CrossRef]

13. Miao, M.; Krishna, J. Mobile payments in Japan, South Korea and China: Cross-border convergence or divergence of business models? Technol. Policy 2016, 40, 182-196. [CrossRef]

14. Pal, D.; Vanijja, V.; Papasratorn, B. An empirical analysis towards the adoption of NFC mobile payment system by the end user. Procedia Comput. Sci. 2015, 69, 13-25. [CrossRef]

15. Wu, J.; Liu, C.; Gardner, D. A study of anonymous purchasing based on mobile payment system. Procedia Comput. Sci. 2016, 83, 685-689. [CrossRef]

16. Sung, S.; Eunbae, K.; Cheong, Y. Mobile payment based on transaction certificate using cloud self-proxy server. ETRI J. 2017, 39, 135-143. [CrossRef]

17. Kshetri, N.; Acharya, S. Mobile payments in emerging markets. IT Prof. 2012, 14, 1520-9202. [CrossRef]

18. Hedman, J.; Henningsson, S. The new normal: Market cooperation in the mobile payments ecosystem. Electron. Commer. Res. Appl. 2015, 14, 305-318. [CrossRef]

19. Keramati, A.; Taeb, R.; Larijani, A.M. The adoption of mobile payment: A descriptive study on Iranian customers. Int. J. Electron. Cstmr. Rel. Manag. 2010, 4, 264-279. [CrossRef]

20. Zhou, T. An empirical examination of continuance intention of mobile payment services. Decis. Support Syst. 2013, 54, 1085-1091. [CrossRef]

21. $\mathrm{Wu}$, R.Z.; Lee, J.H. Use intention of mobile fingerprint payment between UTAUT and DOI in China. J. Dist. Sci. 2017, 15, 15-28. 
22. Goodhue, D.L.; Thompson, R.L. Task-technology fit and individual performance. MIS Quart. 1995, 19, 213-236. [CrossRef]

23. Gebauer, J.; Shaw, M.J.; Gribbins, M.L. Task-technology fit for mobile information systems. J. Inf. Technol. 2010, 25, 259-272. [CrossRef]

24. Lin, W.S. Perceived fit and satisfaction on web learning performance: IS continuance intention and task-technology fit perspectives. Int. J. Hum.-Comput. Stud. 2012, 70, 498-507. [CrossRef]

25. Kuo, R.Z.; Lee, G.G. Knowledge management system adoption: Exploring the effects of empowering leadership, task-technology fit and compatibility. Behav. Inf. Technol. 2011, 30, 113-129. [CrossRef]

26. Smith, C.D.; Mentzer, J.T. Forecasting task-technology fit: The influence of individuals, systems and procedures on forecast performance. Int. J. Forecast. 2010, 26, 144-161. [CrossRef]

27. Lepanto, L.; Sicotte, C.; Lehoux, P. Assessing task-technology fit in a PACS upgrade: Do users' and developers' appraisals converge? J. Digit. Imaging 2011, 24, 951-958. [CrossRef] [PubMed]

28. Yen, D.C.; Wu, C.S.; Cheng, F.F.; Huang, Y.W. Determinants of users' intention to adopt wireless technology: An empirical study by integrating TTF with TAM. Comput. Hum. Behav. 2010, 26, 906-915. [CrossRef]

29. Tam, C.; Oliveira, T. Understanding the impact of $m$-banking on individual performance: DeLone \& McLean and TTF perspective. Comput. Hum. Behav. 2016, 61, 233-244.

30. Venkatesh, V.; Moriss, M.G.; Davis, G.B.; Davis, F.D. User acceptance of information technology: Toward a unified view. MIS Quart. 2003, 27, 425-478. [CrossRef]

31. Venkatesh, V.; Thong, J.Y.; Xu, X. Consumer acceptance and use of information technology: Extending the unified theory of acceptance and use of technology. MIS Quart. 2012, 36, 157-178. [CrossRef]

32. Morosan, C.; DeFranco, A. It's about time: Revisiting UTAUT2 to examine consumers' intentions to use NFC mobile payments in hotels. Int. J. Hosp. Manag. 2016, 53, 17-29. [CrossRef]

33. Alalwan, A.A.; Dwivedi, Y.K.; Rana, N.P.; Algharabat, R. Examining factors influencing Jordanian customers' intentions and adoption of internet banking: Extending UTAUT2 with risk. J. Retail. Consum. Serv. 2018, 40, 125-138. [CrossRef]

34. Zhao, D.J.; Huang, J.S.; Su, S. The effects of trust on consumers' continuous purchase intentions in C2C social commerce: A trust transfer perspective. J. Retail. Consum. Serv. 2019, 50, 42-49. [CrossRef]

35. Kaur, R.; Neeraj, C.; Batraa, K. Trust management in social internet of things: A taxonomy, open issues, and challenges. Comput. Commun. 2020, 150, 13-46.

36. Zhang, T.; Tao, D.; Qu, X.; Zhang, X.; Zeng, X.; Zhu, H.; Zhu, H. Automated vehicle acceptance in China: Social influence and initial trust are key determinants. Transport. Res. C-Emerg. 2020, 112, 220-233. [CrossRef]

37. McKnight, D.H.; Cummings, L.L.; Chervany, N.L. Initial trust formation in new organizational relationships. Acad. Manag. Rev. 1998, 23, 473-490. [CrossRef]

38. Li, X.; Hess, T.J.; Valacich, J.S. Why do we trust new technology? A study of initial trust formation with organizational information systems. J. Strateg. Inf. Syst. 2008, 17, 39-71. [CrossRef]

39. Chen, Y.H.; Barnes, S. Initial trust and online buyer behavior. Ind. Manag. Data Syst. 2007, 1, 21-36. [CrossRef]

40. $\mathrm{Hu}, \mathrm{X}$.; Wu, G.; Wu, Y.; Zhang, H. The effects of web assurance seals on consumers' initial trust in an online vendor: A functional perspective. Decis. Support Syst. 2010, 48, 407-418. [CrossRef]

41. Cocosila, M.; Trabelsi, H. An integrated value-risk investigation of contactless mobile payments adoption. Electron. Commer. Res. Appl. 2016, 20, 159-170. [CrossRef]

42. Zhuang, H.; Leszczyc, P.T.L.P.; Linc, Y. Why is price dispersion higher online than offline? The impact of retailer type and shopping risk on price dispersion. J. Retail. 2018, 94, 136-153. [CrossRef]

43. Zhou, T. Understanding users' initial trust in mobile banking: An elaboration likelihood perspective. Comput. Hum. Behav. 2012, 28, 1518-1525. [CrossRef]

44. Benamati, J.S.; Fuller, M.A.; Serva, M.A.; Baroudi, J.A. Clarifying the integration of trust and TAM in e-commerce environments: Implications for systems design and management. IEEE T. Eng. Manag. 2010, 57, 38-93. [CrossRef]

45. Chang, H.H. Intelligent agents technology characteristics applied to online auctions' task: A combined model of TTF and TAM. Technovation 2008, 28, 564-577. [CrossRef]

46. Wang, H.; Tao, D.; Yu, N.; Qu, X. Understanding consumer acceptance of healthcare wearable devices: An integrated model of UTAUT and TTF. Int. J. Med. Inform. 2020, 139, 104156. [CrossRef]

47. Bozorgkhou, N. An internet shopping user adoption model using an integrated TTF and UTAUT: Evidence from Iranian consumers. Manag. Sci. Lett. 2015, 5, 199-204. [CrossRef]

48. Wu, R.Z.; Lee, J.H. The Comparative study on third party mobile payment between UTAUT2 and TTF. J. Dist. Sci. 2017, 15, 5-19.

49. Wu, B.; Chen, X. Continuance intention to use MOOCs: Integrating the technology acceptance model (TAM) and task technology fit (TTF) model. Comput. Hum. Behav. 2017, 67, 221-232. [CrossRef]

50. Zhou, T.; Lu, Y.; Wang, B. Integrating TTF and UTAUT to explain mobile banking user adoption. Comput. Hum. Behav. 2010, 26, 760-767. [CrossRef]

51. Shih, Y.Y.; Chen, C.Y. The study of behavioral intention for mobile commerce: Via integrated model of TAM and TTF. Qual. Quant. 2013, 47, 1009-1020. [CrossRef]

52. Tian, X.F.; Wu, R.Z.; Lee, J.H. Use intention of chauffeured car services by O2O and sharing economy. J. Dist. Sci. 2017, 15, 73-84.

53. Wu, R.Z.; Lee, J.H. The use intention of mobile travel apps by Korea-visiting Chinese tourists. J. Dist. Sci. 2017, 15, 53-64. 
54. Zhou, T. An empirical examination of initial trust in mobile banking. Internet Res. 2011, 21, 527-540. [CrossRef]

55. Brengman, M.; Karimov, F.P. The effect of web communities on consumers' initial trust in B2C e-commerce websites. Manag. Res. Rev. 2012, 35, 791-817. [CrossRef]

56. Susanto, A.; Lee, H.; Zo, H.; Ciganek, A.P. User acceptance of internet banking in Indonesia: Initial trust formation. Inf. Dev. 2013, 29, 309-322. [CrossRef]

57. Kim, G.; Shin, B.; Lee, H.G. Understanding dynamics between initial trust and usage intentions of mobile banking. Inform. Syst. J. 2009, 19, 283-311. [CrossRef]

58. Djamaludin, C.I.; Foo, E.; Corke, P. Establishing initial trust in autonomous delay tolerant networks without centralised PKI. Comput. Secur. 2013, 39, 299-314. [CrossRef]

59. Yang, S.C.; Hung, W.C.; Sung, K.; Farn, C.K. Investigating initial trust toward e-tailers from the elaboration likelihood model perspective. Psychol. Market. 2006, 23, 429-445. [CrossRef]

60. Hoque, R.; Sorwar, G. Understanding factors influencing the adoption of mHealth by the elderly: An extension of the UTAUT model. Int. J. Med. Inform. 2017, 101, 75-84. [CrossRef]

61. Lee, J.; Kim, K.; Shin, H.; Hwang, J. Acceptance factors of appropriate technology: Case of water purification systems in binh dinh, Vietnam. Sustainability 2018, 10, 2255. [CrossRef]

62. Oliveira, T.; Thomas, M.; Baptista, G.; Campos, F. Mobile payment: Understanding the determinants of customer adoption and intention to recommend the technology. Comput. Hum. Behav. 2016, 61, 404-414. [CrossRef]

63. Sarkar, S.; Chauhan, S.; Khare, A. A meta-analysis of antecedents and consequences of trust in mobile commerce. Int. J. Inform. Manag. 2020, 50, 286-301. [CrossRef]

64. Zhou, T. The effect of initial trust on user adoption of mobile payment. Inf. Dev. 2011, 27, 290-300. [CrossRef]

65. Zhang, T.L.; Lee, J.H. A study on the use intention of easy mobile payment services. E-biz. Stud. 2016, 17, $203-218$.

66. Macedo, I.M. Predicting the acceptance and use of information and communication technology by older adults: An empirical examination of the revised UTAUT2. Comput. Hum. Behav. 2017, 75, 935-948. [CrossRef]

67. Afshan, S.; Sharif, A. Acceptance of mobile banking framework in Pakistan. Telemat. Inform. 2016, 33, 370-387. [CrossRef]

68. Yi, M.Y.; Yoon, J.J.; Davis, J.M.; Lee, T. Untangling the antecedents of initial trust in web-based health information: The roles of argument quality, source expertise, and user perceptions of information quality and risk. Decis. Support Syst. 2013, 55, $0167-9236$. [CrossRef]

69. Hair, J.F.; Black, W.C.; Babin, B.J.; Anderson, R.E. Multivariate Data Analysis, 7th ed.; Prentice Hall: Upper Saddle River, NY, USA, 2010.

70. Voorhees, C.M.; Brady, M.K.; Calantone, R.; Ramirez, E. Discriminant validity testing in marketing: An analysis, causes for concern, and proposed remedies. J. Acad. Market. Sci. 2015, 44, 119-134. [CrossRef] 